\title{
Analysis of high caesarean section rates: the second step after audits using the Ten Group Classification System
}

\author{
M Goonewardene ${ }^{1}$, M Peiris ${ }^{2}$, S Kariyawasam ${ }^{2}$, S Mallawaaratchi ${ }^{2}$, D Kadawathage ${ }^{2}$, \\ L Sanjeewa $^{2}$, P Widanapathirana ${ }^{2}$, I Sandeepani ${ }^{2}$
}

\begin{abstract}
Objective To identify possible methods of reducing high caesarean section rates in a tertiary care hospital.
\end{abstract}

Method Analysis of birth weight of neonates, maternal age and indications for caesarean section in the groups identified by a modification of Robson's 10 Group Classification of caesarean section (TGCS), which contribute significantly to the high caesarean section rates in the University Obstetric Unit, Teaching Hospital Mahamodara, Galle Sri Lanka during 2010 - to 2014.

Results Among nulliparous women, at term, having a singleton fetus, with a vertex presentation (NTSV) who underwent a caesarian section $25.6 \%$ delivered neonates weighing between $2500 \mathrm{~g}$ and $2999 \mathrm{~g}$. Among multiparous women, at term, with no previous caesarean section, having a singleton fetus with a vertex presentation (MTSV) who underwent a caesarian section, those delivering neonates weighing between $2500 \mathrm{~g}$ and $2999 \mathrm{~g}$ ranged from $25.6 \%$ to $34.6 \%$. Indications for ante partum caesarean section included fetal distress, subfertility, increased maternal age and cephalo-pelvic disproportion in NTSV, and fetal distress, vaginal varices, and a bad obstetric history in MTSV. Among multiparous women with one previous caesarean section undergoing repeat caesarean section, $29.8 \%$ delivered neonates weighing between $2500 \mathrm{~g}$ and $2999 \mathrm{~g}$. Women $\geq 35$ years had a higher risk of caesarean section, irrespective of whether they were nulliparous or multiparous, and whether they had a previous caesarean section or not.

Conclusion A reduction in caesarean section rates in NTSV and MTSV, and women with one previous caesarean section, especially in those with fetuses weighing $2500 \mathrm{~g}$ - 2999g, should be considered. Increased maternal age and subfertility per se should not be routine indications for antepartum caesarean section. Antepartum caesarean section for vaginal varices and cephalo-pelvic disproportion should be avoided. The diagnosis of fetal distress should be improved.

Ceylon Medical Journal 2017; 62:149- 158

DIO: http://doi.org/10.4038/cmj.v62i3.8518

\section{Introduction}

Caesarean Section rates in the University Obstetric Unit at Teaching Hospital Mahamodara, Galle (THMG) Sri Lanka has increased from 13\% in 1985 to $31.4 \%$ in 2014. Robson's 10 Group Classification of caesarian section (TGCS) is a global standard used for assessing, monitoring and comparing caesarian section rates within and between healthcare facilities, nationally and internationally [1 -6]. Using a modified version of Robson's TGCS, the main groups contributing to the high caesarian section rates in the University Obstetric Unit at the Teaching Hospital Mahamodara, Galle from 2010 - to 2014 have been identified [7-9]. Following the adoption of appropriate remedial measures in 2010 the caesarian section rates markedly decreased from $32.2 \%$ in 2010 to $26 \%$ in $2011 / 12$ ( $p<0.001)$, but increased again to $>30 \%$ thereafter $(p<0.001)$, although there was a reducing trend overall $(p<0.001)$. Neonatal and perinatal mortality rates had markedly decreased from 2010 to 2014. Maternal admissions for special care too decreased from 2010 to $2011 / 12(p<0.001)$, but although increased again up to $2014(p<0.001)$, but there was a reducing trend overall $(p<0.001)$.

Audit of caesarian sections using the TGCS per se cannot explain the reasons for high caesarian section rates. A more detailed secondary analysis, of the underlying circumstances and indications for caesarian section, is needed to identify possible remedial measures which can reduce the high caesarian section rates [4-6]. The concept of a 'standard primipara' originally described in England, and later changed to a nulliparous term singleton vertex (NTSV) in America, includes groups 1, 2A and 2B of Robson's TGCS [10,11]. Caesarian section rates in NTSV, which have been shown to be correlated with overall caesarian section rates, are used to measure and compare caesarian section rates and monitor quality of care between institutions nationally and internationally as well as in a particular unit prospectively [11-14].

\footnotetext{
${ }^{I}$ Department of Obstetrics and Gynaecology, International Medical University, Clinical Campus, Seremban, Malaysia.

${ }^{2}$ University Obstetrics and Gynaecology Unit, Teaching Hospital, Mahamodara, Galle, Sri Lanka.

Correspondence: MG, E-mail: <IndraMalikRodrigo@imu.edu.my>. Received 21 October 2016 and revised version accepted 24 July 2017.
} 
In the University Obstetric Unit Mahamodara, in 2014, using the modified Robson's TGCS, the five leading groups in order of priority were; multiparous women at term with one previous caesarian section with a singleton fetus in a vertex presentation (Group 5A), NTSV who underwent antepartum caesarian section (Group 2B), NTSV with spontaneous onset of labour (Group 1), multiparous women at term with $>1$ previous caesarian section with a singleton fetus in a vertex presentation (Group 5B), and NTSV with induction of labour (Group 2A). Vaginal birth after caesarian section had increased from $15 \%$ in 2010 to $25.8 \%$ in $2011 / 12$ but it had decreased again to $<15 \%$ in 2013 and 2014 [9]. in In Ireland and USA, increased caesarian section rates in NTSV are mainly due to increased rates in the induction of labour group (Group 2A) and the spontaneous onset of labour group (Group 1), but not due to antepartum caesarian section (Group 2B ) [11-14]. However, in the University Obstetric Unit at the Teaching Hospital Mahamodara, Galle, during the periods of study, among the NTSV, the largest contribution (44.5\%) to caesarian sections was Group 2B while Group 2A contributed 29\% and Group 1 contributed 26.5\% [9]. Multiparous women at term with no previous caesarian section with a singleton fetus in a vertex presentation (MTSV), ie Groups 3, 4A and 4B, is also an important combined group. Co-morbid conditions and obstetric complications alone may not account for the increased caesarian section rates in elderly women [15]. This had been observed in our unit too. Furthermore, it had been observed that cephalo-pelvic disproportion was a frequent justification for antepartum and intra partum caesarian sections in NTSV as well as elective repeat caesarian sections in Group 5A in the unit. The mean birth weight of singleton babies delivered by women with uncomplicated pregnancies and spontaneous onset of labour and delivering vaginally without any obstetric intervention between 37 and 41 weeks gestation in the unit was 2996 g (95\% CI 2976$3017 \mathrm{~g}$ ). (Attanayake and Goonewardene, unpublished data). Therefore the objective of the current study was to study the birth weights of neonates, maternal age and the indications for caesarian section, in the groups identified as contributing significantly to the high caesarian section rates in the unit during four periods of study between 2010 and 2014. This would enable the identification of possible remedial measures to reduce the high caesarian section rates in the unit.

\section{Methods}

A secondary analysis was carried out on the data obtained by prospective study of caesarian sections in the University Obstetric Unit at Teaching Hospital Mahamodara, Galle from 2010 to 2014.
Ethical approval had been obtained for this study from the Ethical Review Committee of the Faculty of Medicine, University of Ruhuna, and administrative approval was obtained from the Directors of the Hospital. All caesarian sections in the groups of the modified Robson's TGCS, which on baseline audits were found to have contributed significantly to the high caesarian section rates in the unit were analysed. The analysed data was collected during the periods $1^{\text {st }}$ March to $31^{\text {st }}$ December 2010, $1^{\text {st }}$ July 2011 to $31^{\text {st }}$ March 2012, $1^{\text {st }}$ February 2013 to $31^{\text {st }}$ January 2014 and $1^{\text {st }}$ February to $31^{\text {st }}$ July 2014 . The birth weights of the neonates in these groups had been obtained using an electronic weighing scale (Asco, Alexander Scales Company, Ahmadabad, India). The birth weights of these babies, the maternal age and the indication for caesarian sections, were studied. The maternal age in women who underwent caesarian section during the periods of study in 2013 and 2014 were compared with a sample of vaginal deliveries in 2013 and 2014.

The means and 95\% confidence intervals (95\% CI) were calculated for continuous variables and compared using the $\mathrm{t}$ test. Proportions were calculated for categorical data and the Chi Square trend was used to assess trends over the four periods of study. Chi Square test was used for comparisons between two periods of study. Increased maternal age was defined as age $\geq 35$ years. Odds Ratios were calculated to identify the association between increased maternal age and risk of caesarian section in nulliparous and multiparous women with and without previous caesarian sections. The IBM Statistical Package for Social Sciences (SPSS) version 20 was used for the analysis.

\section{Results}

Among women who delivered a neonate weighing between $2500 \mathrm{~g}$ and $2999 \mathrm{~g}$ the percentage who underwent caesarian section was NTSV $32.2 \%$, MTSV $31.2 \%$ and women with one previous caesarian sections $29.8 \%$. (Table 1 ). Age $\geq 35$ years, was an independent risk factor for caesarian section in women without a previous caesarian section (OR $1.495 \%$ CI 1.2-1.7) as well as in women with a previous caesarian section (OR 2.0 95\% CI 1.62.7).

Antepartum fetal distress which was the main indication for caesarian section in Group 2B showed a significant increase from $17.5 \%$ in $2011 / 12$ to $26.3 \%$ in $2013(p<0.020)$. Although, it had decreased to $16 \%$ in 2014 , there was an increasing trend over the four periods of study $(p<0.001)$. Maternal age as an indication for caesarian section in Group 2B increased from $1.5 \%$ in 2010 to $9.6 \%$ in 
2014 but the trend was not significant. Subfertility as the indication for caesarian section in Group 2B showed a peak of $17.5 \%$ in $2011 / 12$ which decreased to $5.9 \%$ in 2014 . But this trend was not significant. In Group 2B, an antenatal diagnosis of cephalopelvic disproportion as the indication for caesarian section was $3.9 \%$ in 2010 and $7 \%$ in $2011 / 12$ (Table 2). Of the $104 \mathrm{NTSV}$ who were delivered by antepartum caesarian section due to subfertility, 37 delivered babies with birth weight between 2500 $2999 \mathrm{~g}$, seven were $<30$ years of age and 15 were between $30-34$ years of age. Of the 63 NTSV who were delivered by antepartum caesarian section because they were 'elderly', two were $<35$ years of age and 27 delivered babies weighing $2500-2999 \mathrm{~g}$ at birth. Of the 44 NTSV who were delivered by antepartum caesarian section due to cephalo-pelvic disproportion, five babies had a birth weight of 2500$2999 \mathrm{~g}$, all mothers were $<40$ years of age and two were $<30$ years of age (Table 3 ).

In Group 4B, vaginal varices was the main indication for caesarian section in 2010 . The rate has decreased since then $(p=0.010)$. However, it continues to contribute significantly $(8 \%)$ to the caesarian section rate. Antepartum fetal distress as an indication for caesarian section showed an increasing trend from 2010-2014 ( $p=0.014$ ) (Table 4). Of the 355 MTSV who underwent antepartum caesarian section, the indication for caesarian section was vaginal varices in $53(14.9 \%)$. Twenty one of them delivered babies with a birth weight between 2500 2999 g, 19 women were $<30$ years of age. One was only 24 years of age, in her second pregnancy and she delivered a baby weighing 2600g (Table 5). In Group 2A (NTSV after induction of labour) and Group 1 (NTSV after spontaneous onset of labour) fetal distress was the indication for caesarian section in 31\%- 53\% during the four periods of study. Similarly, fetal distress was the indication for caesarian section in $45 \%-71 \%$ in Group 4A (MTSV after induction of labour) and Group 3 ( MTSV after spontaneous onset of labour) during the four periods of study.

\section{Discussion}

Approximately one in three babies delivered by elective, antepartum caesarian section in NTSV, MTSV and women with one previous caesarian section, weighed between $2500 \mathrm{~g}$ and $2999 \mathrm{~g}$ at birth. This is a matter of great concern, because in the unit, the mean birth weight of a singleton baby delivered vaginally, following spontaneous onset of labour, with no obstetric intervention is approximately $3000 \mathrm{~g}$. Although the estimated fetal weight per se may have not been the only reason for deciding on an antepartum caesarian section in these women, it is unlikely that other reasons would have made major contributions to the decision making process.
Therefore, if the high caesarian section rate in the unit is to be reduced, concerted efforts are needed to reduce rates of caesarian section for average sized babies weighing between $2500 \mathrm{~g}-2999 \mathrm{~g}$. The clinical and ultrasonic assessment of estimated fetal weight too must be improved as other studies carried out in the unit have shown that the estimated fetal weight is sometimes grossly inaccurate. In any case, there is no justification for elective, antepartum caesarian section for cases of suspected cephalo-pelvic disproportion, unless there is obvious, gross cephalopelvic disproportion which is currently extremely rare. The 19 NTSV in Group 2B who had babies weighing between 2500- $3499 \mathrm{Kg}$ could most probably have been allowed trials of labour, instead of elective, antepartum caesarian section for cephalopelvic disproportion. As antepartum fetal distress was the main indication for caesarian section in Groups 2B (primigravidae) and Group 4B ( multigravidae), and accounted for approximately one in five caesarian section in these groups, the high false positive rates associated with an abnormal cardiotocograph (CTG) should be appreciated and complementary tests such as the fetal acoustic stimulation test should also be carried out when appropriate. Furthermore, evaluation of the clinical scenario and the previous and current status of the fetus and the mother, and a good understanding of the pathophysiological basis of and the types of cardiotocographic abnormalities together with improved interpretation of cardiotocographs, are also important before making a decision and embarking on a caesarian section.

It is difficult to ignore the anxiety of older mothers as well as that of the attending clinician, as to whether the baby could be delivered safely, vaginally. This could account for the increased risk of caesarian section with increasing maternal age and these results are consistent with that of a large study from Canada [15]. However it is inappropriate to label nullipara as 'elderly' if they are $<35$ years of age. Furthermore, with proper clinical evaluation and counseling a vast majority of mothers between 35-40 years of age could be allowed a trail of labour, in the absence of any other significant obstetric or medical complication. Twenty one percent of women who had an antepartum caesarian section for 'subfertility' were less than 30 years of age and $33 \%$ of them delivered babies weighing between $2500 \mathrm{~g}-2999 \mathrm{~g}$. Another 38\% were between 30-34 years of age and $38 \%$ of them delivered babies weighing between $2500 \mathrm{~g}-2999 \mathrm{~g}$. This suggests that a significant proportion of these women could have been allowed a trial of labour. If the contribution from Group 5B is to be reduced, the primary caesarian section rates needs to be reduced and vaginal births after caesarian section needs to be increased. A consensus recommendation for the safe prevention of primary caesarean delivery includes recommendations on the management of the first and second stages of labour, 
fetal heart rate monitoring, induction of labour, fetal malpresentations, suspected fetal macrosomia, excessive maternal weight gain and twin gestations [16]. These recommendations and international guidelines for the conduct vaginal births after caesarian section should be seriously considered, adapted according to local needs, and incorporated into clinical practice [17-20].

It is not good practice that "vaginal varices" and cephalo-pelvic disproportion continue to be indications for elective, ante partum caesarian section in groups $4 \mathrm{~B}$ and $2 \mathrm{~B}$ respectively. The vaginal varices are often misinterpretation of the normal physiological changes of pregnancy. A trial of labour should be allowed for cephalo-pelvic disproportion. Although the caesarian section rates have significantly increased during 2013 and 2014, maternal admissions for monitoring and intensive care have only shown a modest, non significant increase after significant reduction from 2010 to $2011 / 12$. Therefore, the increase in caesarian section rates is probably not due to increased maternal obstetric complications. Furthermore, the proportion of neonates admitted to the special care baby unit has been virtually static from 2010 to 2014, indicating that the decrease in neonatal mortality rates from 2010 to 2014 is probably due to improved neonatal care facilities in the hospital and not the increasing caesarian section rates. Further analyses would be required to establish all the factors responsible for the final decision in carrying out a caesarian section, which is beyond the scope of this study. Although direct cause and effect relationships, and the precise contributions of the birth weight and the age of the mother to the high caesarian section rates in the unit have not been established, it is reasonable to postulate that the decision making process and the counseling of women regarding the safe delivery of their babies appears to be suboptimal, and that remedial measures could be adopted. Similar studies should be carried out in other units and comparisons should be made at local, regional, national and international level, in order to identify appropriate methods which could be adopted to safely reduce high caesarian section rates.

The strength of the current study is that after the audit using the modified TGCS, this secondary analysis has identified measures which could be adopted to reduce the high caesarian section rate in the unit. The gaps in the periods of data collection during the five years of the preliminary audits, due non availability of appropriately trained data collectors, was the main limitation. However, during the periods of study the data collection was complete. The minimum continuous period of data collection was six months, and seasonal variations are unlikely to have a major impact on the findings.
In conclusion, concerted efforts are needed to change the attitudes of the health care team in order to improve decision making and to adequately counsel pregnant women regarding the safe delivery of their babies, especially when the estimated fetal weight is between $2500 \mathrm{~g}$ and $2999 \mathrm{~g}$. An increase of vaginal births after caesarian section and trials of labour in NTSV and MTSV should be considered. Maternal age per se, especially in women less than 40years of age, and subfertility per se especially in women less than 30years of age, with babies weighing $2500 \mathrm{~g}$ and $2999 \mathrm{~g}$, should not be considered as contraindication for the conduct of a careful trial of labour. Antepartum caesarian sections for vaginal varices and possible cephalo-pelvic disproportion should be avoided. The diagnosis of fetal distress should be improved.

\section{Conflicts of interest}

There are no conflicts of interest.

\section{References}

1. Robson M, Hartigen L, Murphy M. Methods of achieving and maintaining an appropriate caesarean section rate. Best Pract Res Clin Obstet Gynaecol 2013; 27: 297-308.

2. Betran AP, Vindevoghel N, Souza JP, Gulmezolgu AM, Torlani MR. A systematic review of the Robsons classifications for Caesarean section: what works, doesn't work and how to improve it .PLoS ONE 2014; 9 (6): e 97. DOI: 10.1371 / journal.pone.0097769.

3. Maso G, Ticcoli M, Montico M, et al. Inter institutional variations of Caesarean delivery rates according to indications in selected obstetric populations: A prospective multi center study. Bio Med Res Int 2013. Article ID 786563, 9 pages, http:// dx.doi.org/10.1155/2013/786563.

4. Robson M. The Ten Group Classification System (TGCS) - a common starting point for more detailed analysis. BJOG 2015; 122: 701.

5. Le Ray C, Blondel B, Prunet C, Khireddine I, Denux-Tharaux C, Goffinet F. Stabilizing the caesarean rates: which target population? BJOG 2015; 122: 690-9.

6. Vogel JP, Betran AP, Gulmezoglu AM. Use of the Robson classification has improved understanding of caesarean section rates in France. BJOG 2015; 122: 700.

7. Goonewardene Malik, Kumara DMA, Jathun Arachchi DR, Vithanage R, Wijeweera R. The Rising Trend in Caesarean Section Rates : Should we and can we reduce it? Sri Lanka J Obstet Gynaecol 2012; 34: 11-8. 
8. Goonewardene M, Manawadu $\mathrm{MH}$, Priyaranjana DV Audit: The Strategy to Reduce the Rising Caesarean Section Rate. J South Asian Federation OG 2012; 4: 5-9.

9. Malik Goonewardene, Balakrishna Bhabu, Imali Chethiyawardhana, et al. Increasing Caesarean Section Rates in a Teaching Hospital in Sri Lanka and the use of a Modification of Robson's Ten Group Classification System for Caesarean Sections. Gin Pol Med Project 2016; 40: 009-015.

10. Cleary R, Beard RW, Chapple J, et al. The standard primay para as a basis for inter unit comparison of maternity care. BJOG 1996; 102: 223-9.

11. Coonrod DV, Drachman D, Hobson P, Manriquez M. Nulliparous term singleton vertex caesarean delivery rate: institutional and individual level predictors. Am J Obstet Gynaecol 2008; 198 (issue 6): pg 694.e1 e11.DOI: 10.1016/j/.ajog.2008.03.026.

12. Brennen DJ, Murphy M, Robson MS. The singleton, cephalic, nulliparous women after thirty six weeks of gestation: Contribution to overall caesarean delivery rates. Obstet and Gynaecol 2011; 117: 273 -9.

13. Main EK, Moore D, Farell B, et al. Is there a useful caesarean birth measure? Assessment of the nulliparous term singleton vertex caesarean birth rate as tool for obstetric quality improvement. Am J Obstet Gynecol 2006; 194: 1644-52.

14. Ehrenthal DB, Jiang $X$, Strobino DM. Labour induction and the risk of a caesarean delivery among nulliparous women at term. J Obstst Gynaecol 2010; 116: 35 - 42.

15. Janoudi G, Kelly S, Yasseen A, Hamam H, Moretti F, Walker M. Factors Associated With Increased Rates of Caesarean Section in Women of Advanced Maternal Age. J Obstet Gynaecol Can 2015; 37: 517-26.
16. The American College of Obstetricians and Gynaecologists \& The Society for Maternal Fetal Medicine. Obstetric care consensus No.1. Safe prevention of the primary cesarean delivery. Am J Obstet Gynecol 2014; 123: 693711.

17. The Royal College of Obstetricians and Gynaecologists. RCOG Green Top Guideline 45. Birth after previous caesarean birth. Oct. 2015, The Royal College of Obstetricians and Gynaecologists. London, England. http://www.rcog.org.uk /en/guidelines-research (accessed 21 August 2016).

18. The Royal Australian and New Zealand College of Obstetricians and Gynaecologists. Birth after previous caesarean section. RANZCOG C-Obs 38, 2014. http:/www.ranzcog.edu.au/component/docman/ doc_download/971-c-obs-38-planned-vaginalbirth-after-caesarean-section-trial-of-labour.html (accessed 21 August 2016).

19. American College of Obstetricians and Gynaecologists (ACOG). Clinical Management Guidelines Vaginal Birth after Previous Caesarean Section. 2010. Available from: http://www.acog.org/Resources-AndPublications/Practice-Bulletins/Committee-onPractice-Bulletins-Obstetrics/Vaginal-BirthAfter-Previous-Cesarean-Delivery. (accessed 2 August 2016).

20. The Society of Obstetricians and Gynaecologists of Canada (SOGC). Guidelines for Vaginal Birth after Previous Caesarean Birth. 2004. Available from: http://sogc.org/wpontent/uploads/2013/01/155E-CPGFebruary2005.pdf. (accessed 21 August 2016). 
Table 1. Caesarean Section rates from 2010-2014 according to the birth weight of the neonate

\begin{tabular}{|c|c|c|c|c|c|c|c|}
\hline $\begin{array}{l}\text { Birth } \\
\text { Weight }\end{array}$ & $\begin{array}{c}\text { Group } 1 \\
N=456\end{array}$ & $\begin{array}{c}\text { Group } 2 A \\
N=461\end{array}$ & $\begin{array}{c}\text { Group } 2 B \\
N=818\end{array}$ & $\begin{array}{c}\text { Group } 3 \\
N=195\end{array}$ & $\begin{array}{c}\text { Group } 4 A \\
N=168\end{array}$ & $\begin{array}{c}\text { Group } 4 B \\
N=355\end{array}$ & $\begin{array}{c}\text { Group } 5 A \\
N=1133\end{array}$ \\
\hline$<2000 \mathrm{~g}$ & $4(0.8 \%)$ & $1(0.2)$ & $37(4.5 \%)$ & $1(0.5 \%)$ & $1(0.5 \%)$ & $13(3.7 \%)$ & $11(1.0 \%)$ \\
\hline $\begin{array}{l}2000 \mathrm{~g}- \\
2499 \mathrm{~g}\end{array}$ & $28(6.1 \%)$ & $30(6.5 \%)$ & $164(20.0 \%)$ & $14(7.1 \%)$ & $11(6.5 \%)$ & $42(11.8 \%)$ & $85(7.5 \%)$ \\
\hline $\begin{array}{l}2500 \mathrm{~g}- \\
2999 \mathrm{~g}\end{array}$ & $147(32.2 \%)$ & $151(32.8 \%)$ & $262(32.0 \%)$ & $58(29.7 \%)$ & $43(25.6 \%)$ & $123(34.6 \%)$ & $338(29.8 \%)$ \\
\hline $\begin{array}{l}3000 \mathrm{~g}- \\
3499 \mathrm{~g}\end{array}$ & $205(45.0 \%)$ & $182(39.5 \%)$ & $249(30.4 \%)$ & $75(38.5 \%)$ & $64(38.0 \%)$ & $113(31.8 \%)$ & $473(41.7 \%)$ \\
\hline$>3500 \mathrm{~g}$ & $72(15.8 \%)$ & $97(21.0 \%)$ & $106(13.0 \%)$ & $47(24.1 \%)$ & $49(29.2 \%)$ & $64(18.0 \%)$ & $226(19.9 \%)$ \\
\hline
\end{tabular}


Table 2. Indications for antepartum caesarean section in Group 2B (nulliparous term singleton vertex)

\begin{tabular}{|c|c|c|c|c|c|}
\hline Indication & $\begin{array}{c}2010 \\
(n=206)\end{array}$ & $\begin{array}{l}2011 / 12 \\
(n=257)\end{array}$ & $\begin{array}{c}2013 \\
(n=167)\end{array}$ & $\begin{array}{c}2014 \\
(n=188)\end{array}$ & $\begin{array}{c}\text { Significance } \\
\mathrm{p}^{*}\end{array}$ \\
\hline Fetal distress $(\%)$ & $31(15.1)$ & $45(17.5)$ & $44(26.3)$ & $30(16.0)$ & $<0.001$ \\
\hline Subfertility(\%) & $25(12.1)$ & $45(17.5)$ & $21(12.6)$ & $11(5.9)$ & 0.444 \\
\hline Elderly mother(\%) & $3(1.5)$ & $\begin{array}{l}27(10.5) \\
\mathrm{p}<0.001\end{array}$ & $15(9.0)$ & $18(9.6)$ & 0.608 \\
\hline $\begin{array}{l}\text { Probable cephalo-pelvic } \\
\text { disproportion }(\%)\end{array}$ & $8(3.9)$ & $18(7.0)$ & $10(6.0)$ & $8(4.3)$ & 0.796 \\
\hline Medical reasons $(\%)$ & $19(9.2)$ & $18(7.0)$ & $16(9.6)$ & $15(8.0)$ & 0.372 \\
\hline Miscellaneous (\%) & $120(58.2)$ & $104(40.5)$ & $61(36.5)$ & $106(56.4)$ & 0.314 \\
\hline
\end{tabular}

*Chi Square trend test 
Table 3. Number of women in Group 2B who underwent antepartum caesarean section between 2010-2014 for 'cephalopelvic disproportion' according to maternal age and the birth weight of the neonate

\begin{tabular}{lclcccc}
\hline \multirow{2}{*}{ Birth weight (grams) } & \multicolumn{5}{c}{ Age (years) } & \multirow{2}{*}{ Total } \\
\cline { 2 - 6 } & $<25$ & $25-29$ & $30-34$ & $35-39$ & $\geq 40$ & \\
\hline $2500-2999$ & 0 & 2 & 0 & 3 & 0 & 5 \\
\hline $3000-3499$ & 1 & 5 & 4 & 4 & 0 & 14 \\
\hline $3500-4150$ & 4 & 10 & 5 & 3 & 3 & 25 \\
\hline Total & 5 & 17 & 9 & 10 & 3 & 44 \\
\hline
\end{tabular}


Table 4. Indications for antepartum caesarean section in Group 4B (multiparous term singleton vertex)

\begin{tabular}{lccccc}
\hline \multicolumn{1}{c}{ Indication } & $\begin{array}{c}2010 \\
(\mathrm{n}=79)\end{array}$ & $\begin{array}{c}2011 \\
(\mathrm{n}=91)\end{array}$ & $\begin{array}{c}2013 \\
(\mathrm{n}=109)\end{array}$ & $\begin{array}{c}2014 \\
(\mathrm{n}=78)\end{array}$ & $\mathrm{p}$ \\
\hline Fetal Distress (\%) & $15(19)$ & $13(14)$ & $36(33)$ & $19(24)$ & 0.032 \\
Vaginal varices (\%) & $19(24)$ & $17(19)$ & $11(10)$ & $6(8)$ & 0.215 \\
Bad Obstetric History (\%) & $9(11)$ & $6(7)$ & $9(8)$ & $2(3)$ & 0.660 \\
& & & & \\
Medical (\%) & $12(15)$ & $13(14)$ & $13(12)$ & $9(12)$ & 0.744 \\
Miscellaneous (\%) & & & & \\
\end{tabular}


Table 5. Antepartum caesarean section for ' vaginal varices' between 2010-2014 in multiparous term singleton vertex (Group 4B) according to maternal age and the birth weight of the neonate

\begin{tabular}{lcccccc}
\hline \multicolumn{1}{c}{$\begin{array}{c}\text { Birth weight of } \\
\text { neonate (grams) }\end{array}$} & $<25$ & $25-29$ & $30-34$ & $35-39$ & $\geq 40$ & Total \\
\hline$<2500$ & 0 & 2 & 1 & 2 & 0 & 5 \\
$2500-2999$ & 1 & 10 & 6 & 4 & 0 & 21 \\
$3000-3499$ & 0 & 4 & 6 & 7 & 2 & 19 \\
$3500-4150$ & 0 & 2 & 1 & 5 & 0 & 8 \\
Total & 1 & 18 & 14 & 18 & 2 & 53 \\
\hline
\end{tabular}

This is an open-access article distributed under the terms of the Creative Commons Attribution License, which permits unrestricted use, distribution, and reproduction in any medium, provided the original author and source are credited. 